\title{
Three Things to Do with Knowledge Ascriptions
}

\section{Tammo Lossau}

\begin{abstract}
Any good theory of knowledge ascriptions should explain and predict our judgments about their felicity. I argue that any such explanation must take into account a distinction between three ways of using knowledge ascriptions: (a) to suggest acceptance of the embedded proposition, (b) to explain or predict a subject's behavior or attitudes, or (c) to understand the relation of knowledge as such. The contextual effects on our judgments about felicity systematically differ between these three types of uses. Using such a distinction is, in principle, open to both contextualist and pragmatic invariantist accounts of knowledge ascriptions. However, there are some implications pertaining to the use of the "method of cases" in the debate about knowledge ascriptions.
\end{abstract}

Ascriptions of knowledge carry different messages depending on the context in which they were uttered. Accordingly, which knowledge ascriptions are felicitous varies from context to context. Attributor contextualism seeks to explain this by providing mechanisms that determine these standards given information about the context of attribution. Invariantist accounts refuse to accept such variations as part of the semantic meaning (in some narrower sense) of knowledge ascriptions themselves but try to explain said variance by providing a pragmatic explanation. I will argue that both contextualists (in their semantics) and invariantists (in their pragmatics) can only provide reasonably precise theories if they incorporate a distinction of three ways of using knowledge ascriptions: roughly, we can say "S knows that P” either to (1) introduce or affirm P as an appropriate assumption for the purposes of the current conversation thereby focusing on the embedded proposition; or to (2) introduce to the conversation that S has a certain epistemic state ("knowledge of P") that will allow us to explain or 
predict S's attitudes or behavior better, thereby focusing on the subject; or (3) to put forward a claim pertaining to the meaning or "nature" of knowledge, thereby focusing on the relation of knowledge. Which way a knowledge ascription is used leads to differences regarding how information about the context can be mapped to the resulting standards of knowledge.

I will briefly discuss the respective situations of contextualism and invariantism. Then I will motivate the distinction between three ways of using knowledge ascriptions and discuss its effect within the framework of relevant alternatives. I believe that the effects will carry over to other frameworks, but I find them easiest to understand and to pin down precisely when appealing to a domain of relevant possibilities.

\section{Accounting for Variance}

It is widely acknowledged that ascriptions of knowledge to the same subject with the same evidence may be judged to be felicitous in one context but not in another. Instances of this include Keith DeRose's (1992) bank cases in which the "stakes" are different, cases in which a possibility of error that speakers were not attending to is brought up (in an unobjectionable way), and cases in which specific norms such as those of scientific inquiry are brought into play. Any linguistically satisfying account of knowledge ascriptions must explain there divergent judgments of felicity.

I will here focus on two familiar strategies for dealing with this phenomenon: (a) contextualism, i.e. accounts that directly allow the meaning of knowledge ascriptions to vary from context to context, and (b) pragmatic invariantism, i.e. the claim that there is a semantic level of meaning at which knowledge ascriptions are context-insensitive, but also a derivative pragmatic level of meaning - the meaning that is actually conveyed - which is flexible in the required way and which can be computed based on the semantic meaning and facts about the context. So both strategies recognize a level of meaning - which 
may be pragmatic meaning - which varies from context to context and which more or less aligns with our judgments about felicity. ${ }^{1}$

While all sides agree that there is contextual variation in what we require for a subject to be described as knowing that P, surprisingly little has been said on how exactly these requirements are determined. For example many versions of relevant alternatives theories simply stay officially neutral on the notion of contextual relevance of a possibility (Goldman 1976, Dretske 1981) or work with a notion of closeness or resemblance of possibilities that is context-sensitive in an underexplained way (Nozick 1981, Lewis 1996). More recently, we have seen more precise accounts that bring in notions such as Stalnakerian pragmatic presuppositions (Blome-Tillman 2014) or presuppositions of the current question under discussion (Schaffer and Szabó 2014) that can be used to determine a domain of relevant possibilities. On the invariantist side, there has been some hesitation to commit to a precise account of pragmatic mechanisms as this is not part of the invariantist's central claim (e.g. Unger 1975) - but this invites the objection that the invariantist may be unable to actually account for our judgments of felicity. Many invariantists have thus invoked conversational implicatures (Schaffer 2004, Davis 2007, Douven 2007, Rysiew 2007) or Bachian implicitures (Brown 2006) which has invited a number of objections (e.g. DeRose 1998, Blome-Tillman 2013, Dinges 2016, 2018) I will not discuss here.

What is remarkable is that all of the accounts mentioned aim for a general explanation and prediction of our judgments about the felicity of knowledge ascriptions. Of course the pragmatic presuppositions in different contexts will be extremely divergent, as will be the implicatures generated by an utterance, but still these accounts suggest a unified mechanism taking us from the utterance or semantic meaning

1 The invariantist can allow exceptions of this. For example, if one assumes an infallibilist version of invariantism this puts one in a position to say that it is infelicitous to assert so-called concessive knowledge attributions of the form "I know that P but I cannot rule out all possible errors” because one would thereby be explicitly contradicting the semantic meaning. 
combined with information about the context of assertion to the conveyed meaning which is the basis of our judgments about felicity. I will argue that these accounts can only be successful if they appeal to at least one crucial distinction between three ways of using knowledge ascriptions. A mechanism that is blind to this distinction is bound to mismatch our judgments of felicity one way or another.

\section{The three things}

The accounts referenced above make it natural to ask in any given case why a speaker decides to use a knowledge ascription. What is their goal in making such an utterance? I suggest that we can best answer this question by pointing out which aspect of the schema "S knows that P" the participants of the conversation primarily attend to. There are three options:

- the first relatum, i.e. the subject S, resulting in a subject-focused knowledge ascription (SFKA).

- the second relatum, i.e. the proposition $\mathrm{P}$, resulting in a proposition-focused knowledge ascription (PFKA).

- The relation of knowing itself, resulting in a knowledge-focused knowledge ascription (KFKA).

The difference between these is a difference in how the knowledge ascription relates to the kind of speech act the speaker is performing - we differenciate here by which aspect of the knowledge ascription is central to the topic of the conversation. These three options are not mutually exclusive, so there can be multi-purpose knowledge ascriptions. There also, of course, may be a mismatch between how the speaker intends their utterance to be understood and how the hearer actually understands it. As I want to be neutral on whether the suggested threefold distinction applies to the semantic or pragmatic side of meaning (to not take side on the debate about semantic invariantism), I will leave these cases 
aside. Here I will only discuss what I take to be the most common successful uses of knowledge ascriptions which I think allow for a clear categorization.

First proposition-focused knowledge ascriptions (PFKAs). We often ascribe knowledge to ourselves and others to assert the embedded proposition in a way that expresses a strong conviction in it. Such PFKAs compare naturally to simple assertions (“P.”) or hedged assertions (“It seems that P.”, "My best guess is that P.”). The subject $\mathrm{S}$ is relevant here insofar as it is credited as the (or one) source of that contribution - so, of course, we cannot simply pick an arbitrary subject when using a PFKA. However, the main point of asserting a PFKA is not to express something about S's epistemic state but to recommend that the discourse participants accept $\mathrm{P}^{2}$ Consider the following four examples:

BANK (DeRose’s (1992, 913) Bank case B):

Husband: The line at the bank is long. Should we just come back tomorrow [Saturday]? I was at the bank on Saturday morning only two weeks ago and discovered that it was open until noon. Wife: We have just written a very large and very important check. If our paychecks are not deposited into our checking account before Monday morning, the important check we wrote will bounce leaving us in a very bad situation. Banks do change their hours. Do you know the bank will be open tomorrow?

2 PFKAs come closest to a view of the use of knowledge ascriptions that can be traced back to Edward Craig (1990). On Craig's own view, knowledge ascription save the purpose of identifying an accessible informant who is likely enough to be right about $\mathrm{P}$ for the purposes at hand. In the case of propositional knowledge ascriptions (but not in the case of knowing-wh), the role of the informant is less emphasized on my account. A version of it that comes closer to what I present here as the account of PFKAs is an idea due to Klemens Kappel (2010) and Christoph Kelp (2011), namely what Patrick Rysiew (2012) calls the certification view. According to this “it is [a] central role of 'know(s)' to certify information as being such that it may, even should, be taken as settled, for purposes of one's practical and theoretical deliberations” (Rysiew 2012, 275) I agree with Rysiew, though, that it is implausible that something like Craig's suggestion is the only role knowledge ascriptions play - examples later in the paper will show this. 
Husband: Well, no. I'd better go in and make sure.

HAT (essentially from Austin 1946, 176, footnote)

Mary: Is Mr. Wearahat in the club room? A student wants to see him.

John: Yes, I know he’s in because his hat is in the hall.

\title{
DINOSAUR
}

Me: Any news on the question which color dinosaurs had?

Paleontologist: Well, we know now that some of them had quite colorful feather but we can still say very little about their skin color.

\begin{abstract}
ALIBI
Assistant: Does Mr. Suspect have an alibi for Wednesday from 3 to 4 PM?

Detective: No, and Mrs. Boss knows that he wasn’t at work at that time.
\end{abstract}

In all of these cases knowledge ascriptions are used such that whatever proposition is embedded can be assumed for the purpose or question at hand. In the case of BANK the denial of knowledge conveys that it is not safe, even with the given evidence, to operate on the assumption that the bank will be open on Saturday. Meanwhile in HAT we do not have the same high stakes so John can say that it is fine to operate on the assumption that Mr. Wearahat is in the club room. DINOSAUR is not connected to a practical decision like the first two cases are - I am here just curious what dinosaurs looked like. Still there is a question driving the conversation and the paleontologist provides a partial answer embedded in a knowledge ascription. Finally, ALIBI is distinct in that the subject of the knowledge ascription is not part of the conversation. Still, by using a knowledge ascription (instead of indirect speech, for 
example) the detective conveys that we can assume that Mr. Suspect was indeed not at work on Wednesday afternoon. Mrs. Boss is here mentioned as the source of our information, which is relevant because she might be an important witness, but there is no apparent interest in her epistemic state per se.

The point of PFKAs is to suggest that we accept the embedded proposition at least for current purposes. Roughly, this will be felicitous if the evidence of the subject of the knowledge ascription warrants this suggestion. The framework of relevant alternatives is helpful to make a few more precise remarks here: David Lewis (1996) suggests that that S knows that P iff S’s evidence eliminates every possibility in which not-P that cannot be properly ignored. With respect to PFKAs we can say that the purpose of our conversation helps determine which possibilities are ignored in the evaluation of the knowledge ascription. For instance, following Michael Blome-Tilmann we could say that the pragmatic presuppositions in the context of attribution restrict the domain of possibilities to those consistent with them; or we could follow the line of Jonathan Schaffer and Zoltán Gendler Szabó and say that the presupposition of the question under discussion limits the domain of possibilities in this way, potentially together with strategic assumptions we make with respect to this question (see Roberts 2012 for background on this); or we could say that the domain of possibilities is pragmatically limited due to the shared assumption that speakers are acting cooperatively. My point here is not to commit to one such strategy but to point out that these notions describe the conversational context of attribution without saying anything about the subject of the knowledge ascription. In the case of PFKAs, we only need information about the context of attribution itself to determine the felicity conditions of a knowledge ascription. That is to say, it depends exclusively on the context of attribution which possibilities the subject needs to be able to eliminate in order to count as knowing that P in that context. It is worth to comment specifically on ALIBI because this case is a bit of an outlier. Most PFKAs attribute knowledge to some participant of the conversation (often the speaker herself) or a group that 
includes most or all participants of the conversation ("we know that...”), where it may often be unclear who exactly belongs to that group. In ALIBI, Mrs. Boss is not present in the conversation. The evaluation of the knowledge ascription can still be straightforward as above if her epistemic position is the same as that of the participants of the conversation in the relevant respects. However, the question arises how to evaluate this knowledge ascription if Mrs. Boss lacks relevant information that is available in the context of attribution. For instance, suppose that Assistant and Detective have just watched the surveillance tapes from the lobby and both accept (in mutual awareness of each other's acceptance) that Mr. Suspect was not in the lobby at the time. Suppose further that Mrs. Boss was in the office (which does not have video surveillance) all afternoon and can only rule out that Mr. Suspect was in the office at that time. Finally, suppose that there is no other place at work besides the lobby and the office where Mr. Suspect might have been. Now, the evidence Mrs. Boss has gives Assistant and Detective what they are looking for - with this evidence they will be able to rule out that Mr. Suspect was at work at the time of interest. On the other hand Mrs. Boss cannot, from her own perspective, rule this out. Speaking in general terms and ignoring the context of attribution for a moment, it is clear that Mrs. Boss does not have knowledge.

This general judgment seems to be mainly driven by the fact that this knowledge ascription is naturally interpreted as a SFKA, e.g. it may (perhaps falsely) predict that she thinks Mr. Suspect is guilty. It is interesting to ask what happens when we use it as a PFKA, if such a use is even possible. Let us try to take the perspective of someone in the context given above: imagine you have, without any remaining doubt, ruled out that Mr. Suspect was in the lobby. The question whether he was at work then becomes materially equivalent to the question whether he was in the office. The evidence Mrs. Boss has can answer the latter question, but because you identify that question with the former question, you simply take it to answer that question, too. In this way it may become felicitous to say that Mrs. Boss knows that Mr. Suspect was not at work. But this is far from clear, and I have seen my 
own intuitions differ from those of others here. What we can say, in any case, is this: if we can employ PFKAs to establish certain propositions by attributing knowledge to people who have a piece of information that is crucial to us, but who lack important background we have, then these knowledge ascriptions ought to be evaluated taking everything for granted that is taken for granted in the context of attribution.

Second, subject-focused knowledge ascriptions (SFKAs). These are knowledge ascriptions uttered with the goal of providing some information about the "knower", for example to explain or predict her behavior or her attitudes. Unlike PFKAs, these do not contrast with assertion or hedged assertion, but with ascriptions of belief, conviction, suspicion and many other propositional attitudes. Two examples:

\section{MOCK-FIN}

Mike: Do you think we can trick Valery into thinking you’re Finnish?

Me: No, she knows that I don’t speak the language.

\section{CURFEW}

Police Officer: Were you guys planning to stay here?

Drunk: No, we know curfew starts in five minutes.

In MOCK-FIN, a SFKA is used to predict Valery's behavior in a hypothetical scenario and thereby advise against a certain course of action. In CURFEW, Drunk ascribes knowledge to her own group to "predict” or announce their future behavior. In both of these cases, the embedded proposition is also represented as true because knowledge is factive. However, the truth of that proposition is not itself 
immediately relevant to the opening question. ${ }^{3}$ The SFKA conveys something relevant only because it ascribes knowledge to this particular subject.

In contrast to PFKAs, the felicity condition of SFKAs cannot be straightforwardly derived from the background of the context of assertion; but neither can they be explained simply by reference to the subject's epistemic state. On the one hand, knowledge ascriptions represent the embedded proposition P as true, so its felicity must require that it is felicitous to represent $\mathrm{P}$ as true in the context of attribution. Furthermore, the background assumptions of the context of attribution do seem to carry over to these cases. For example, working with common ground for the moment, if it is not common ground in the context of attribution that we are not deceived by an evil demon (i.e. this is a skeptical context), SFKAs then will not be felicitous if they ascribe knowledge of the external world to anyone. But there are also contexts of attribution where participants of the conversation share a great deal of common ground. Speakers in such contexts may judge a SFKA felicitous even if neither they themselves nor the subject of the knowledge ascription are in a position to rule out some possibilities that are inconsistent with their common ground.

On the other hand and in contrast to PFKAs, there are limits to this effect. Specifically, knowledge ascriptions of this kind cannot be felicitous if the subject does not accept part of what the participants of the conversation accept as common ground and if the relevant propositions are presupposed in the knowledge ascription. For instance, the SFKA in MOCK-FIN cannot be felicitous in virtue of the fact

3 Nonetheless, the truth of P may be indirectly relevant. To see this, consider the contrast with belief attributions, which can also serve as a way of explaining or predicting attitudes or behavior. Had I said in MOCK-FIN “she believes I don’t speak the language”, the prediction that we cannot fool Valery would have failed insofar as this may be a false belief. If I did speak Finnish, it would be easy to correct her belief and then make her think I was actually Finnish. However, using "knows" clarifies that her epistemic position is more stable than that and therefore allows different predictions. A similar difference between knowledge and belief attributions arises from cases of true beliefs that are based on inadequate evidence. 
that it is common ground between the participants of the conversation that I do not speak Finnish - if Valery does in fact not accept that I do not speak Finnish and the participants of the conversation are aware of this fact, then my utterance will clearly be infelicitous. At least one of the reasons for this is the fact that in such a case the knowledge attribution would completely fail to predict or explain Valery's behavior or attitudes. Compare this to the variant of ALIBI that I discussed above where Mrs. Boss's behavior or attitudes are presumed to be irrelevant to the conversation. This suggests that we can only limit the domain of possibilities for SFKAs to those consistent with common ground insofar as the subject also accepts the relevant propositions. But note also that, per the preceding paragraph, propositions that the subject accepts but that are not accepted by the participants of the conversation do not limit the domain of possibilities as it is infelicitous to represent them as true in the context of attribution. So in contrast to PFKAs, SFKAs convey an epistemic state that requires being able to rule out all possibilities that are not presupposed to be false or accepted to be false or properly ignored or excluded in some other way (depending on your favorite approach to knowledge ascriptions) by both the participants of the conversation in the context of attribution and the subject herself.

Finally, knowledge-focused knowledge ascriptions (KFKAs). Note that both PFKAs and SFKAs are made to convey something relevant to some independent question or purpose. But there are a few contexts in which knowledge itself is the topic of the conversation. These are almost exclusively philosophical contexts; in a sense, making knowledge the topic of a conversation simply is to make a conversation philosophical. It is natural, then, to contrast these with claims containing semantic ascent such as "It is false that S knows that P" where the knowledge ascription itself is made a topic of the conversation, too. Of course, epistemology has produced a vast range of such cases. Here are three examples that appear to fall in this category:

GETTIER (Gettier 1963, here a version from Weinberg et al. 2001) 
Bob has a friend, Jill, who has driven a Buick for many years. Bob therefore thinks that Jill drives an American car. He is not aware, however, that her Buick has recently been stolen, and he is also not aware that Jill has replaced it with a Pontiac, which is a different kind of American car. Does Bob really know that Jill drives an American car, or does he only believe it?

MOORE (an unfairly short version of Moore 1939)

Here is one hand, there is another. This proves that I have two hands, and therefore I know that I have two hands. But this means I also know that an external world exists.

\section{WITTGENSTEIN (Wittgenstein 1969, 151)}

I should like to say: Moore does not know what he asserts he knows, but it stands fast for him, as also for me; regarding it as absolutely solid is part of our method of doubt and enquiry.

GETTIER simply concerns the question whether Bob knows that Jill drives an American car. In the context of an experimental study (which is where this version of the problem was used) this is asked as an "out of the blue” question. In the context of Gettier's original paper, there was a broader question in the background, but this question, too, concerned the concept of knowledge or how we could define knowledge. MOORE and WITTGENSTEIN are examples of philosophers arguing about the question whether we know that an external world exists. Moore uses the claim that he knows that he has two hands to argue for the further claim that he knows that an external world exists. The latter claim is an immediate answer to the question whereas the former claim is best understood as a part of a strategy of answering that question. In WITTGENSTEIN, both claims are rejected. As both represent positions by legitimate philosophers, it is therefore natural to suppose that in these contexts there is room for disagreement. 
GETTIER straightforwardly asks us whether Bob knows that Jill owns an American car. Note that it may not be clear to the someone being polled like this whether this question concerns the truth or the felicity of that statement. But let us take it as a question regarding the truth of "Bob knows that Jill owns an American car." There is something presupposed or shared as common ground between the pollster and the pollee about the situation here, namely the truth of the case description. This description includes some statements about what Bob thinks and is (not) aware of as well as some information about the reality of things (partly conveyed by the factivity of "awareness"). There is also the presumption that there are no other very unusual circumstances relevant to the question applying to Bob. ${ }^{4}$ The pollee is asked to suppose these things. Beyond this, the context and the question asked do not seem to introduce any further statement into the background on which the pollee is asked to give her opinion. ${ }^{5}$ In particular, it is clear enough that the embedded proposition is true (supposing the case description), so we cannot treat this as a PFKA, and there is no indication of further interest in the subject's mindset or behavior, although it is still possible that some pollees treat this as a SFKA. There then appears to be no context-related reason for the pollee to ignore any possibilities when evaluating the knowledge ascription. Given all this, we should assume that the pollee will (or should) evaluate simply the semantic truth conditions of the knowledge ascription "Bob knows that Jill owns an American car" in the pollee's own context (if this is relevant). ${ }^{6}$ Note that therefore the context of

4 This is a pragmatically conveyed aspect of the case description: it can be assumed that the case description will contain all relevant aspects of the situation given that the pollee is asked for a judgments about it. This is not a problem for the idea that the pollee is asked to evaluate the semantic meaning of knowledge ascriptions: they can be asked to make this evaluation in a way that involves pragmatic processes that set up the question.

5 Except possibly the statement that the pollee is capable of answering the question.

6 This is completely compatible with a contextualist account. For example, Lewisians can say that the relevant truth conditions are infallibilist as there is no restriction of the domain of relevant possibilities. 
attribution here is identical to the context of evaluation ${ }^{7}$ - unlike in BANK, where the knowledge ascription was uttered by a subject within the case and that subject was denying that knowledge ascription as an answer to an independent question.

MOORE and WITTGENSTEIN are different insofar as they do not talk about any specific subject's knowledge of anything, but about knowledge that we all supposedly have. Again, the embedded proposition here is not by itself important to us: Wittgenstein begins On Certainty by stating: "If you do know that here is one hand, we'll grant you all the rest” (OC 1). But neither is any specific individual of interest to us: while the examples above are technically concerned with G.E. Moore, he only appears as a representative of humanity. Once again, the question then concerns the relation of knowledge itself and once again it seems that it is to be answered by applying the semantic meaning of knowledge ascriptions to these examples. What is interesting, though, is that Moore and Wittgenstein disagree on whether we actually have the relevant knowledge - and beyond this, we still have no agreed upon semantics of knowledge ascriptions despite decades of philosophical inquiry. There are two possible explanations for this: (a) we have not identified any reliable means of accessing the semantic meaning of knowledge ascriptions, or (b) in some cases we confuse questions about the semantic meaning with questions about the quotidian felicity of knowledge ascriptions. Discussing this further goes beyond the scope of this paper.

To sum up, here is an overview over the three types of uses of knowledge ascriptions that I have discussed:

\begin{tabular}{|l|l|l|l|}
\hline \multicolumn{1}{|c|}{ compare to } & \multicolumn{1}{c|}{ goal } & \multicolumn{1}{c|}{ contextual effects } \\
\hline PFKAs & $\begin{array}{l}\text { assertion; hedged } \\
\text { assertion }\end{array}$ & $\begin{array}{l}\text { establish embedded proposition } \\
\text { in discourse }\end{array}$ & full contextual effects \\
\hline
\end{tabular}

7 Which is not to say that we could not have KFKAs where those are distinct: we could have set GETTIER up as a case about a subject that is posited a Gettier case and is asked for her opinion. 


\begin{tabular}{|l|l|l|l|}
\hline SFKAs & $\begin{array}{l}\text { belief ascription; other } \\
\text { attitude ascriptions }\end{array}$ & $\begin{array}{l}\text { explain or predict subject's } \\
\text { attitudes or behavior }\end{array}$ & $\begin{array}{l}\text { as PFKAs insofar as shared by } \\
\text { subject }\end{array}$ \\
\hline KFKAs & semantic ascent & $\begin{array}{l}\text { understand the relation of } \\
\text { knowledge }\end{array}$ & only explicit modifications \\
\hline
\end{tabular}

Table 1: Summary of the three types of uses for knowledge ascriptions.

Table 1 gives the natural contrast class for the knowledge ascription, the goal with which these are put forward, and the contextual effects, i.e. the extent to which certain possibilities may be discarded as irrelevant to the evaluation of the knowledge ascription (e.g. because they are ruled out by common ground). The crucial aspect is that the conveyed content depends on different aspects of the context: PFKAs will be felicitous if the subject has evidence that meets the contextually required standards - in terms of relevant alternatives, the subject needs to have evidence that eliminates all non-P possibilities that are not ruled out by features of the context of assertion. In the case of SFKAs, felicity will further require that the subject accepts the proposition that guide these standards, too - they will need to accept propositions that rule out the omitted possibilities. In the case of KFKAS that are successsfully interpreted as such, we will judge them felicitous based on their semantic truth. Thus our judgments of felicity depend on different features depending on the type of knowledge ascription used, and therefore any explanation of these judgments needs to accommodate this distinction.

One final caveat on this distinction is in order: I have not provided any conclusive evidence that the threefold distinction I suggested here exhausts all possible ways of using knowledge ascriptions. The fundamental question that led to this distinction was the question for the goal of the relevant utterance of "S knows that P" - I have suggested that this goal may be to understand S's epistemic position, to understand our own epistemic position, or to understand knowledge itself. I think that these are the most typical goals associated with knowledge ascriptions (the first two being more typical). The idea that some aspect of the utterance "S knows that P" (i.e. "S", "knows", or "that P") must be our focus 
when making this utterance may make it seem plausible that the distinction is indeed exhaustive. However, I see no principled reason why there could not be other goals for using knowledge ascriptions. My point here merely is that there are at least the three types of uses discussed, and that the contextual effects will greatly vary depending on the type in question. If there are further types, what I have said about the three types discussed here will hold up, but we will need to do further work to explore how context affects the conveyed content for those additional types.

\section{$\underline{\text { Ramifications }}$}

I have argued that there is a distinction of three ways of using knowledge ascriptions that must be taken into account when we try to explain our judgments of felicity of knowledge ascriptions. In principle, the distinction I have suggested is compatible both with contextualist and invariantist accounts. My point here is not to argue for one side of that dispute, but rather to suggest that both sides should allow for a distinction like this. However, there are a few methodological upshots that I would like to comment on in closing.

Before this, let me note that I do not claim that the distinction I have advocated is the only distinction that needs to be taken into account. In particular, Mikkel Gerken’s (2017) directive force account that argues we often (but not always) treat knowledge ascriptions as appropriate assumptions to base practical decisions on and evaluate them accordingly. Whether or not knowledge ascriptions are treated this way may well be an important distinction among PFKAs.

As I have noted, nothing that I have said overthrows either contextualism or invariantism. However, I think that there are a few noteworthy points relevant to some of the arguments made in that debate. The disagreement between contextualists and invariantists is a disagreement about the semantic meaning of knowledge ascriptions; both sides can agree on what is ultimately communicated by uttering them. 
Given this, it seems that to settle the dispute it would seem easiest to look at KFKAs, as our judgments about them should be directly driven by the semantic meaning. However, contextualists could object that KFKAs are made in very specific contexts and will not give us the full picture of the semantic truth conditions. It is also noteworthy though that bank cases - which are central to some versions of contextualism - are instances of PFKAs. These cases are put forward as essentially involving a decision to be made, and the knowledge ascription in question concerns a proposition that this decision depends on. Therefore, these cases generate an interest in the truth of that proposition (and the level of warrant we have for it). ${ }^{8}$

However, that is not to say that bank cases are irrelevant. To the contrary, we need to account for all knowledge ascriptions in a systematic way. While bank cases in principle lend themselves to a pragmatic account, it is not entirely clear how the details of such an account should look like. Much of this will depend on whether the invariantist starts with an infallibilist or a fallibilist semantics of knowledge ascriptions.

As I said, insofar as semantics is concerned KFKAs are the most straightforward source of evidence even though their scope as evidence may be limited. However, it is important to re-emphasize a cautionary note: the way I have construed KFKAs, their felicity is determined by their semantic meaning (in that context). It is very easy to slip into evaluating the same knowledge ascription as $a$ PFKA or SFKA. For instance, it can be very easy to side with Moore that we know that we have hands simply because for all intents and purposes, we can reasonably assume that we have hands. But if we

8 To transform a bank case into a case involving a KFKA, one would need to invoke the knowledge ascription from outside the case. For example, a philosopher commenting on DeRose's case could claim that Husband really doesn't know that the bank will be open tomorrow. But note that an invariantist may find it much easier to disagree with this philosophical utterance than to say that Husband's in-case denial of knowing this is infelicitous. On the other hand, it is far from clear that the invariantist is right either: inasmuch as I have any intuitions at all about whether Husband really knows that the bank will be open tomorrow, I suspect them to be theory-driven. 
do this, we are no longer taking this statement as a KFKA. Rather, we are evaluating it as a PFKA by imagining contexts in which the question whether we have hands is of any further importance. To keep focus on the notion of knowledge itself is surprisingly difficult. Peter Unger $(1975,85)$ suggests that this can be achieved by asking whether someone really knows a certain proposition, and this is what happens in GETTIER. But there may be further implications to that modification, too.

To end on a more optimistic note, a source of evidence that may prove very helpful are crosscontextual judgments. The reason is this: if we explain the felicity judgments on knowledge ascriptions in pragmatic terms, we should expect that these effects become less salient if the knowledge ascription is evaluated from a different context that lacks the invoked features. However, if we think that the semantic features of knowledge ascriptions are responsible for the judgment of felicity, we should expect these judgments to remain relatively unaffected - at least insofar as the subject keeps a focus on the relevant features of the context of attribution. In particular, we should be interested in crosscontextual judgments between contexts containing KFKAs and contexts containing PFKAs, as these are most different from one another with respect to potential pragmatic effects that are in place. ${ }^{9}$

\section{$\underline{\text { References }}$}

Austin, J. 1946. 'Other Minds.' Proceedings of the Aristotelian Society, Supplementary Volumes, 20(1): 122-187.

Blome-Tillmann, M. 2013. 'Knowledge and Implicatures.' Synthese, 190(18): 4293-4319.

------- 2014. Knowledge and Presuppositions. Oxford: Oxford University Press.

9 I would like to thank Michael Williams, Mikkel Gerken, the audiences at the Tübingen Masterclass 2017, the 2017 European Congress of Analytic Philosophy in Munich, and the Hammond Society Colloquium at Johns Hopkins, as well as the anonymous reviewers for helpful comments on the core ideas of this paper. 
Brown, J. 2006. 'Contextualism and Warranted Assertability Manoeuvres.' Philosophical Studies, 130(3): 407-435.

Craig, E. 1990. Knowledge and the State of Nature: An Essay in Conceptual Synthesis. New York: Oxford University Press.

Davis, W. 2007. 'Knowledge claims and context: loose use.’ Philosophical Studies, 132(3): 395-438.

DeRose, K. 1992. 'Contextualism and Knowledge Attributions.' Philosophy and Phenomenological Research, 52(4): 913-29.

------ 1998. 'Contextualism: An Explanation and Defense.' In J. Greco and E. Sosa (eds.), The Blackwell Guide to Epistemology, pp. 187-205. Malden, MA: Blackwell.

Dinges, A. 2016. 'Skeptical pragmatic invariantism: good, but not good enough.' Synthese, 193(8): 2577-2593.

------ 2018. Knowledge, intuition and implicature. Synthese 195(6): 2821-2843.

Douven, I. 2007. 'A pragmatic dissolution of Harman’s paradox.' Philosophy and Phenomenological Research, 74(2): 326-345.

Dretske, F. 1981. 'The Pragmatic Dimension of Knowledge.’ Philosophical Studies, 40(3): 363-378.

Gerken, M. 2017. On Folk Epistemology. How we Think and Talk about Knowledge. Oxford: Oxford University Press.

Gettier, E. 1963. 'Is Justified True Belief Knowledge?’ Analysis, 23(6): 121-123.

Goldman, A. 1976. Discrimination and Perceptual Knowledge. The Journal of Philosophy 73(20): 771-791.

Kappel, K. 2010. 'On Saying that Someone Knows: Themes from Craig.’ In A. Haddock, A. Millar, and D. Pritchard (eds.), Social Epistemology, pp. 69-88. Oxford: Oxford University Press.

Kelp, C. 2011. 'What Is the Point of “Knowledge” Anyway?’ Episteme, 8(1): 53-66. 
Lewis, D. 1996. 'Elusive Knowledge.’ Australasian Journal of Philosophy, 74(4): 549-567.

Moore, G. E. 1939. 'Proof of an External World.' Proceedings of the British Academy, 25: 273-300.

Nozick, R. 1981. Philosophical Explanations. Cambridge, MA.: Harvard University Press.

Roberts, C. 2012. 'Information structure in discourse: Towards an integrated formal theory of pragmatics.' Semantics \& Pragmatics, 5 (article 6): 1-69.

Rysiew, P. 2007. ‘Speaking of Knowing.’ Noûs, 41(4): 627-662.

------ 2012. Epistemic Scorekeeping. In Knowledge Ascriptions, eds. J. Brown and M. Gerken, 27094. Oxford: Oxford University Press.

Schaffer, J. 2004. 'Skepticism, Contextualism and Discrimination.' Philosophy and Phenomenological Research, 69(1): 138-155.

Schaffer, J. and Z. Gendler Szabó 2014. 'Epistemic comparativism: a contextualist semantics for knowledge ascriptions.’ Philosophical Studies, 168(2): 491-543.

Unger, P. 1975. Ignorance. A Case for Scepticism. Oxford: Oxford University Press.

Weinberg, J., Nichols, S., and Stich, S. 2001. Normativity and Epistemic Intuitions. Philosophical Topics 29(1): 429-460.

Wittgenstein, L. 1969. On Certainty. Ed. by G.E.M. Anscombe and G.H. von Wright, transl. by D. Paul and G.E.M. Anscombe. Oxford: Blackwell. 